\title{
Conceptual Design and Aerodynamic Analyses of a Generic UCAV Configuration
}

\author{
Carsten M. Liersch* and Kerstin C. Huber* \\ German Aerospace Center (DLR), Braunschweig, Germany
}

\begin{abstract}
Applying DLR's conceptual aircraft design system to military flying wing configurations, the design of a generic UCAV configuration is presented. For its outer shape, the SACCON geometry specified by NATO STO/AVT-161 Task Group was taken. For mission analysis and structural sizing, aerodynamic data from fast and robust conceptual design methods (i.e. potential flow theory) were used. In order to assess the validity of these simple methods for such configurations, a comparison with results from RANS aerodynamics and wind tunnel measurements was performed. The results of this design task were included into the stability and control investigations performed within the AVT-201 task group.
\end{abstract}

\section{Nomenclature}

$C_{A}$

$C_{D}$

$C_{L}$

$C_{N}$

$C_{S}$

$C_{Y}$

$C_{l}$

$C_{m}$

$C_{m x}$

$C_{m y}$

$C_{m z}$

$C_{n}$

$I_{x x}$

$I_{y y}$

$I_{z z}$

$V$
Axial force coefficient [-]

Drag force coefficient $[-]$

Lift force coefficient [-]

Normal force coefficient [-]

Body-fixed side force coefficient [-]

Side force coefficient [-]

Rolling moment coefficient [-]

Pitching moment coefficient [-]

Body-fixed $X$-moment coefficient [-]

Body-fixed $Y$-moment coefficient [-]

Body-fixed $Z$-moment coefficient [-]

Yawing moment coefficient $[-]$

Mass moment of inertia ( $X$-axis) $[-]$

Mass moment of inertia ( $Y$-axis) [ $[-]$

Mass moment of inertia ( $Z$-axis) [ -$]$

Freestream velocity $\left[\frac{\mathrm{m}}{\mathrm{s}}\right]$

$p, q, r \quad$ Rotation rates $\left(X, Y, Z\right.$-axis) $\left[\frac{\circ}{s}\right]$

Conventions

$X, Y, Z$ Coordinate system

Symbols

$\alpha \quad$ Angle of attack $\left[{ }^{\circ}\right]$

$\beta \quad$ Angle of yaw $\left[^{\circ}\right]$

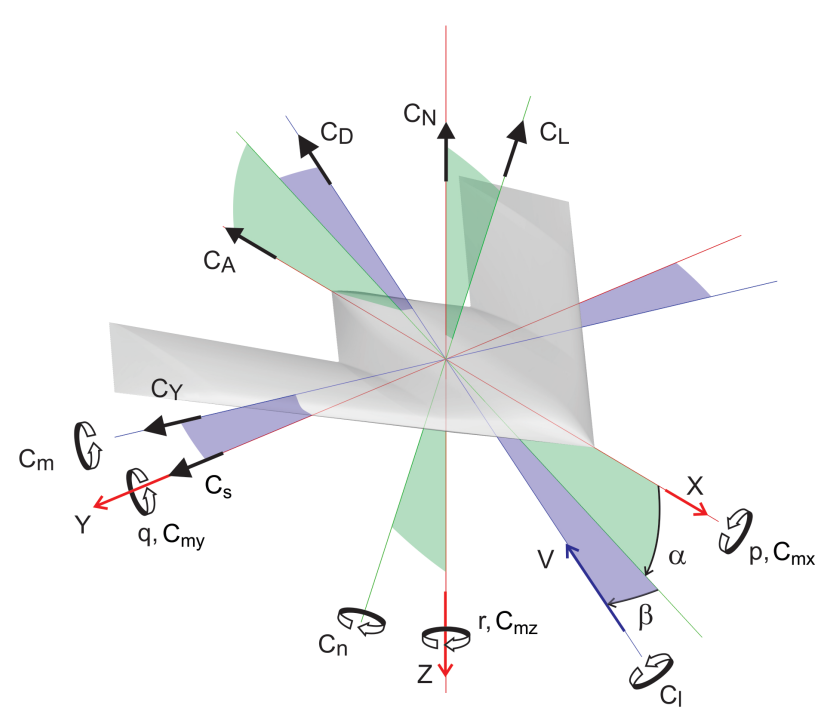

Figure 1. Coordinate system [see Vicroy et al. ${ }^{1}$ ]

\section{Introduction}

A

IRCRAFT design is a higly multidisciplinary task, involving experts from a number of disciplines such as aerodynamics, propulsion, structures, and many others. Even in the early stages of conceptual design it

* Research Scientist, German Aerospace Center, Institute of Aerodynamics and Flow Technology, Lilienthalplatz 7, 38108 Braunschweig. 
is very useful to have all these experts in the loop. This may help to avoid decisions which may later prove as problematic when looking more into detail. Especially the discipline of flight mechanics is often introduced at later stages of design since required data regarding aerodynamics, masses, and control surface efficiencies may not be available before. This late-binding of such a crucial discipline has led to a number of substantial problems during the history of aircraft design and should be prevented by providing comprehensive aircraft data as early as possible. Another advantage of early including disciplinary experts and their physics-based tools into the design process becomes apparent when designing unconventional aircraft configurations such as a highly swept flying wing $\mathrm{UCAV}^{\mathrm{a}}$. In this case, empirical handbook methods might lead to wrong results if the statistical basis from which they were derived does not cover the designed configuration sufficiently.

The concept to include disciplinary experts, their tools and knowledge even in the very beginning of the design process is one of the core concepts of the aircraft design system being developed by DLR ${ }^{\mathrm{b}}$ since $2005 .^{2,3,4}$ The system consists of three parts:

\section{- Data exchange}

A data exchange file format called CPACS $^{c}$ is being developed for the DLR aircraft design system. ${ }^{5}$ CPACS is an XML based data format which is designed to store aircraft data in a hierarchical way. It was introduced mainly to serve as a common language between the disciplinary analysis tools. Two software libraries ${ }^{6}$ called $\mathrm{TiXI}^{\mathrm{d}}$ and $\mathrm{TiGL}^{\mathrm{e}}$ are being developed to ease the use of CPACS. While TiXI provides a simple interface to create, read, modify, and write CPACS datasets, TiGL generates a CAD ${ }^{f}$ model of the aircraft and offers methods to query geometric data from this model. The TiGL-Viewer application can be used to visualise the underlying CAD model. The complete package of CPACS and libraries is available under open source licenses. ${ }^{7,8,9}$

\section{- Disciplinary analysis tools}

The analysis of an aircraft configuration is performed by disciplinary analysis tools which are provided and maintained by the disciplinary experts. For many disciplines, there is already more than one tool available - each one covering a different level of fidelity or using a different way of modeling. What they all have in common is the need to read and write CPACS datasets as input and output. For new tools, it is certainly a good way to use the CPACS data format directly. For legacy codes, which typically have (and shall keep) their own data formats, the best way is to use a so called "toolwrapper". A toolwrapper is a small program which reads a CPACS file, writes an input file for the tool, runs the tool, reads the output file of the tool and finally writes the results as a CPACS file. In order to keep the disciplinary experts in the loop and to avoid a decoupling of the used tools from further development, the tools are not gathered at one location to form a monolithic program. Instead, they are placed on disciplinary tool servers which stay under maintenance and supervision of the corresponding expert. Using a software integration framework, these distributed tools can be plugged together to form process chains for aircraft design and analysis.

\section{- Integration framework}

The software integration framework serves as a sort of construction kit. Here, the disciplinary tools, which are located on distributed servers, can be linked together to create process chains, customised for individual design or analysis tasks. Trade-study tools, different optimisers and other drivers of the process may be applied to get an impression of the sensitivities of the design parameters as well as optimal solutions for specific target functions. Up to now, the commercial ModelCenter framework ${ }^{10}$ was mainly used for this task, but will be replaced by the DLR integration framework $\mathrm{RCE}^{\mathrm{g}}$ in the future. ${ }^{11}$ Just as CPACS, TiXI, and TiGL, RCE is provided under an open source license as well. ${ }^{12}$

This aircraft design system was initially developed for the investigation of commercial transport aircraft. Within some internal research projects the design system was extendend and used for the investigation of a highly swept flying wing UCAV configuration, based on the SACCON ${ }^{\mathrm{h}}$ geometry from the NATO STO/AVT-161 task group.

\footnotetext{
${ }^{\text {a Unmanned Combat Air Vehicle }}$

${ }^{\mathrm{b}}$ German Aerospace Center (Deutsches Zentrum für Luft- und Raumfahrt e.V.)

${ }^{\mathrm{c}}$ Common Parametric Aircraft Configuration Schema

${ }^{\mathrm{d}} \mathbf{T i X I}$ XML Interface

${ }^{\text {e }}$ TiGL Geometry Library

${ }^{\mathrm{f}}$ Computer Aided Design

gRemote Component Environment

${ }^{\mathrm{h}}$ Stability And Control CONfiguration
} 


\section{Conceptual UCAV Design}

The initial design of the SACCON outer shape (see Figure 2) was developed in 2007 and 2008 by partners from AVT-161 in order to have a common, generic UCAV configuration for research purposes. ${ }^{13}$ One of the ideas behind SACCON was to have a geometry which could exactly be reproduced in a windtunnel model as well as in a $\mathrm{CFD}^{\mathrm{i}}$ mesh. The original SACCON geometry has

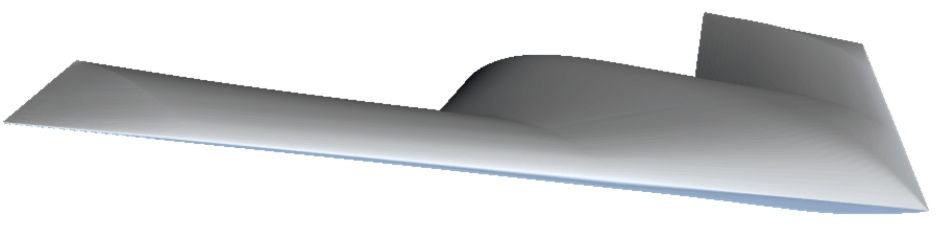

Figure 2. SACCON outer shape a wingspan of approx. $1.54 \mathrm{~m}$ which is well suited to build a windtunnel model from it. The conceptual design task, presented in this article, was to develop a realistic UCAV concept based upon the original SACCON outer shape. This means, that it was only permitted to scale the whole SACCON geometry to a suitable size and to cut out parts for integrating components like control surfaces or engine inlets and nozzles.

In general, each aircraft is designed to fulfill one or more specific design missions. In this context, such a design mission incorporates a payload to be carried and a simplified flight trajectory (consisting at least of altitude and Mach number for a sequence of waypoints). Aside from the mission itself, an aircraft has to meet a number of further boundary conditions like operational requirements and certification rules. For this conceptual design study, only one design mission and a very limited number of additional boundary conditions were specified. The used boundary conditions are composed in Table 1. Figure 3 provides an overview of the profile of the UCAV's design mission.

\begin{tabular}{|l|l|}
\hline Parameter & Value \\
\hline \hline Outer shape & Scaled SACCON geometry \\
Propulsion & 1 or 2 turbofan engines \\
Engine integration & Buried, due to signature reasons \\
Payload storage & internal (due to signature reasons) \\
Payload mass & $1 \times 2000 \mathrm{~kg}$ or $2 \times 1000 \mathrm{~kg}$ \\
Design range & $3000 \mathrm{~km}$ (without refuelling) \\
Fuel reserve & $\approx 45 \mathrm{~min}$ \\
Cruise altitude & $11 \mathrm{~km}$ \\
Cruise Mach number & 0.8 (all altitudes) \\
Stability margin & $2-8 \%$ \\
\hline
\end{tabular}

Table 1. Mission parameters and boundary conditions

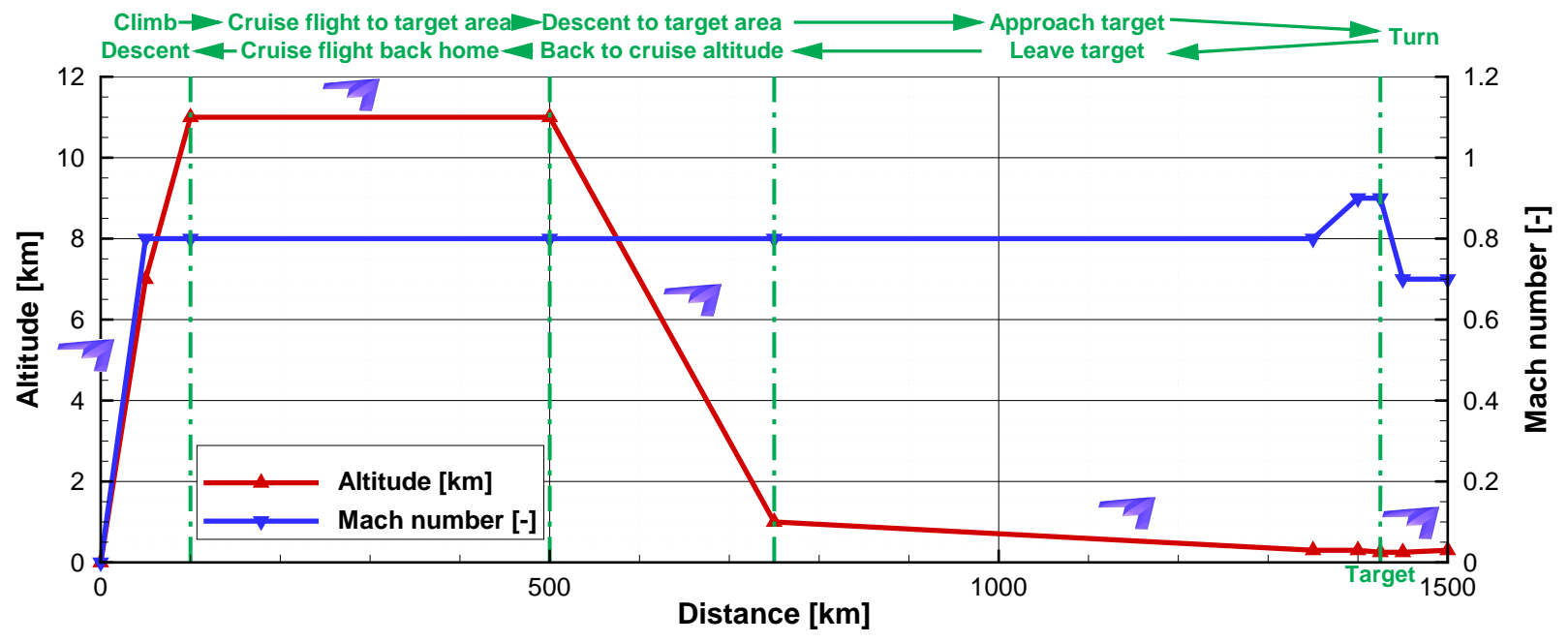

Figure 3. UCAV design mission

${ }^{\mathrm{i}}$ Computational Fluid Dynamics 
The payload mass for the UCAV was defined to be $2000 \mathrm{~kg}$ in total. Due to signature requirements, an internal storage in one or two payload bays is mandatory. A design range of $3000 \mathrm{~km}$ without aerial refuelling was considered sufficient - an extra reserve of approx. 45 minutes is desireable. With this assumption, an operational radius of $1500 \mathrm{~km}$ could be reached. Cruise flight to the target area shall be performed at an altitude of $11 \mathrm{~km}$ with a Mach number of 0.8. In the target area, the UCAV shall descend to an altitude of $300 \mathrm{~m}$ while keeping the Mach number of 0.8. During the last kilometres, it could even descend to $250 \mathrm{~m}$ and accelerate to Mach 0.9 - but due to the fixed outer shape, this is just an optional requirement. In order to keep a good manouverability for this flying wing UCAV without making it laterally instable, a stability margin of $2-8 \%$ was selected. Based on these parameters, an initial estimation of the overall aircraft size and the corresponding take-off mass was made (see Table 2).

\begin{tabular}{|l|cc|cc|}
\hline Parameter & Initial & \multicolumn{2}{|c|}{ Final } \\
\hline \hline Scaling factor (compared to SACCON) & 8.0 & & 10.0 & \\
Wingspan & 12.3 & $m$ & 15.375 & $m$ \\
Maximum take-off mass & 10.0 & $t$ & 15.0 & $t$ \\
Thrust-to-weight ratio & 0.35 & & 0.4 & \\
Static thrust & 35.0 & $k N$ & 60.0 & $k N$ \\
\hline
\end{tabular}

Table 2. Main aircraft parameters

These estimated values were used as a starting point for all further investigations and had to be updated during later stages of the design. Based on knowledge from conventional small fighter/trainer aircraft like the Northrop Grumman F5F Tiger II, the thrust-to-weight ratio was set to a relatively small value of 0.35 , resulting in a required static thrust of

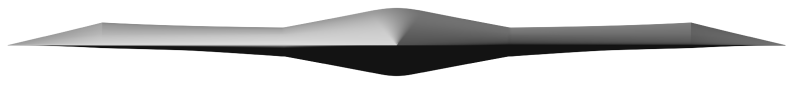
$35 \mathrm{kN}$. Considering the fixed outer shape which is shown in Figure 4, a concept with a central payload bay and two engines aside would offer very limited vertical space for the engines, thus permitting only a low bypass ratio. Some preliminary studies showed that such a configuration would need a much larger scaling factor in order to store enough fuel to reach the specified design range. On the other hand, a single engine is more efficient by default and its location in the middle of the aircraft offers much more vertical space. Hence, this concept was chosen for further investigations. The payload bay was split into two parts which were placed on either side of the engine.

After defining the starting point, the concept was investigated using DLR's conceptual design system. An engine with the required thrust and diameter was designed especially for this configuration and was included alongside the structural topology and other main components of the UCAV. Using the SACCON CAD geometry together with the already defined parameters, a CPACS model of the UCAV was created. This CPACS model, visualised by the TiGL-Viewer in Figure 5, was used as a central data repository being filled up during the design process. Furthermore, a Microsoft Excel spreadsheet with a 2D planform view of the geometry and its main components was created in order to calculate mass breakdown, center of gravity (CG), and mass moments of inertia. In order to be able to investigate changes in center of

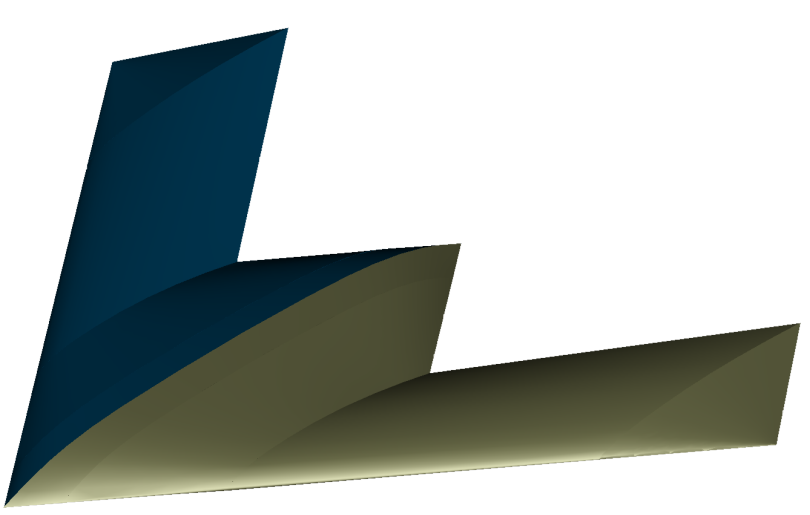

Figure 5. UCAV CPACS geometry model gravity locations and available fuel volume with respect to parameter changes, it was decided to integrate this spreadsheet directly into the process chain - even though it is limited to configurations which are quite similar to the current concept. In the future, a more common tool with similar features is expected to be available within DLR's design system. 
Figure 6 illustrates the complete design process, as it was created for the UCAV design task: Starting from the CPACS source dataset (upper left corner), the workflow splits up into two main branches, which are computed in parallel, and a third branch (upper right corner). The latter is just responsible for visualising the current geometry by using TiGL functionalities.

The first (left) one of the two branches creates a performance deck for the engine. This performance deck contains all relevant engine parameters (e.g. mass flows, temperatures, emissions) over a variety of flight levels, Mach numbers and thrust settings. The propulsion tool "TWdat" which is used here is a database, fed with a number of engines in advance. The engine design itself is performed separately in the gas turbine simulation environment "GTlab".14 The second branch (middle) creates a set of aerodynamic performance maps. The first set contains force and moment coefficients over a variety of Mach numbers, Reynolds numbers, angles of

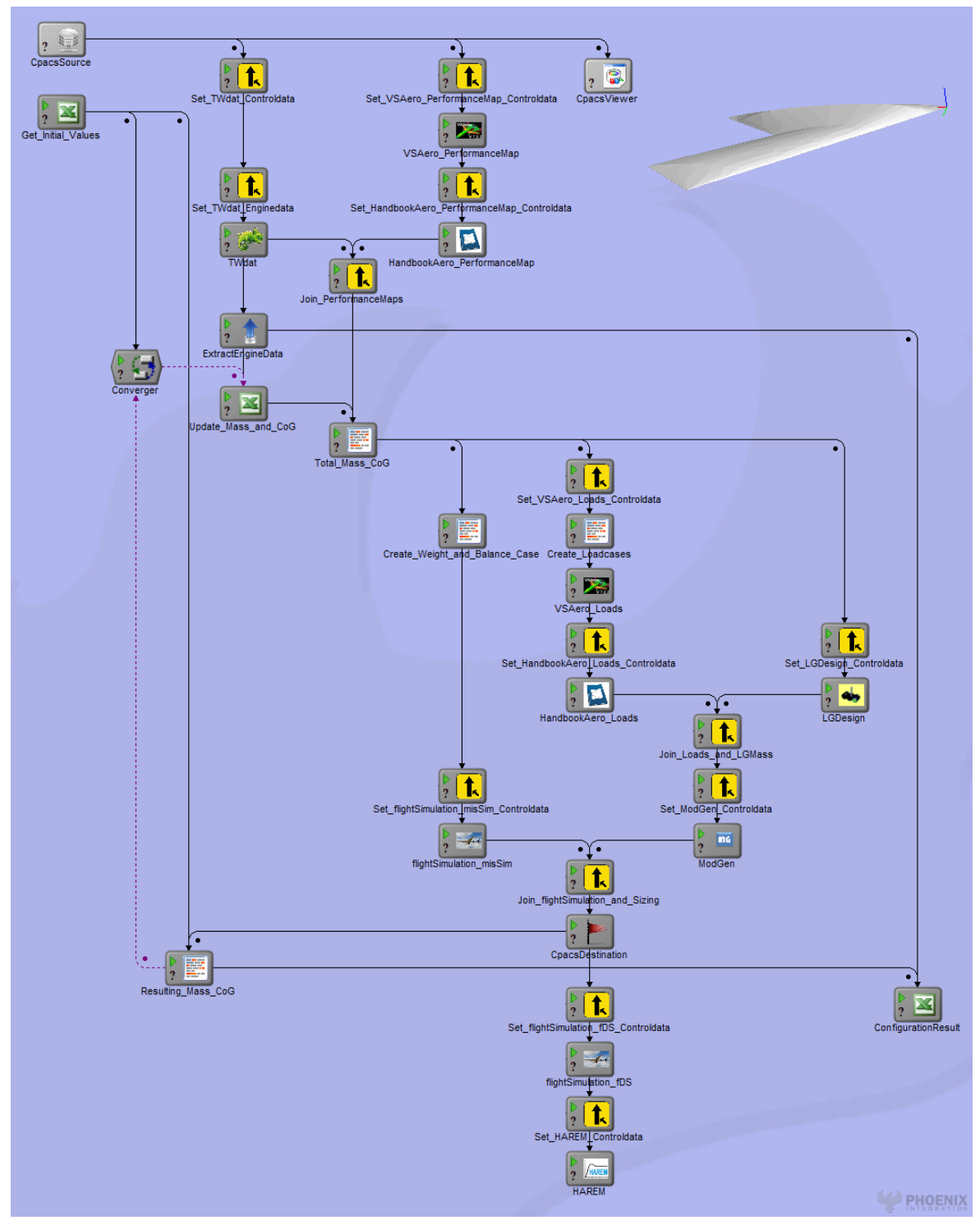

Figure 6. Conceptual design process (ModelCenter) yaw and angles of attack for the "clean" configuration without control surface deflections. On top of this four-dimensional clean configuration dataset, a five-dimensional delta-coefficient performance map is created for each control surface (introducing the control surface deflection as fifth dimension). By superposition of different control surface delta-coefficients with the absolute coefficients of the clean configuration dataset, it is possible to combine the deflections of multiple control surfaces. A third set of aerodynamic performance maps contains the damping derivatives for each point of the clean configuration dataset. Depending on the number of each of the dimensions' entries and on the number of control surfaces, this aerodynamic dataset may grow quite large. In fact, for the example presented here, it contains a number of 57600 entries in total. Even with modern computer systems it is not possible to handle such a number of RANSj-CFD computations in an acceptable timeframe - but using simple, potential flow theory based aerodynamics methods, such a performance deck can be created within a few hours or even within minutes. In this process chain Analytical Methods' commercial "VSAERO" tool ${ }^{15}$ is used in combination with DLR's simple "HandbookAero" method which accounts for skin friction drag and wave drag. Other tools, like DLR's open source "LIFTING_LINE" method, ${ }^{16,17}$ could be used here as a replacement for VSAERO as well. The question about the limitations of potential flow

${ }^{\mathrm{j}}$ Reynolds-Averaged Navier-Stokes equations 
methods and whether they can be used to model such a configuration and the associated flow physics will be discussed in Chapter III.

The results of the propulsion and aerodynamics branches are both joined together into the CPACS dataset and handed over to the "TotalMassCoG" script. Furthermore, the engine's mass and position are directly inserted into the Excel spreadsheet described above. The TotalMassCoG script imports mass data, center of gravity location and mass moments of inertia from this Excel spreadsheet and writes them into the CPACS as well. So at this point of the process chain, the dataset contains updated performance maps and total mass data. The following block is an iterative loop which calculates required fuel, landing gear mass, and structural mass. The left branch contains the tool "flightSimulation" which simulates a flight of the aircraft as specified in the design mission. ${ }^{18}$ As a result, the flight trajectory and the required fuel are written back to the CPACS file. In the second branch, a script selects critical loadcases which are then calculated by the connected aerodynamic tools. Again, VSAERO and HandbookAero are used here, but in this case, the output of the aerodynamic tools is a number of spanwise distributions of the aerodynamic coefficients which can be used for structural sizing. In parallel to the first two branches, the right branch uses the tool "LGDesign" to analyse and size the landing gear. ${ }^{19}$ As a result, it provides landing gear mass and critial ground loadcases which are combined with the spanwise aerodynamic coefficient distributions and fed as an input into the structural sizing tool "ModGen". ModGen creates a structural model of the UCAV and sizes the thicknesses of the elements. ${ }^{20}$ The computed data for the UCAV's structural mass are combined with the fuel mass from the first branch to a resulting UCAV model. Finally the so-called "Converger" module checks, whether the resulting masses differ significantly from the ones used at start of the iteration loop, and, if necessary, it updates the Excel spreadsheet and starts the next iteration.

When the iteration finally has converged, a subsequent analysis process is started: In this case, the flightSimulation tool is used again, but this time it creates a dynamic aircraft model which is handed over to the "HAREM" tool. HAREM is an analysis tool for investigating and evaluating the handling qualities of an aircraft. ${ }^{21,22}$

The whole process chain was created using DLR's conceptual design system and runs completely automatically. In this case, it uses the ModelCenter integration framework for tool coupling and data exchange. Aside from small scripts and other supporting components it contains 7 different disciplinary tools (3 of them are even used twice in different working modes), residing on 6 servers, provided by 5 DLR Institutes, located at 4 different sites distributed over Germany.

As a result from running the process chain, it became obvious that the required fuel volume was nearly two times the available tank volume. Furthermore, it turned out that the payload bays would roughly need twice of the volume available and that the maximum take-off mass would significantly exceed the estimated amount of 10 metric tons. As a consequence, the initially estimated parameters had to be revised: A second global scaling step - this time with a factor of 1.25 (meaning a factor of 10 compared to the SACCON geometry in total) and a new maximum take-off mass of 15 metric tons seemed promising here (see Table 2 on page 4). After this resizing process, the engine had to be re-dimensioned as well. Taking this as an opportunity, the trust-to-weight ratio was also slightly increased to 0.4. The revised engine uses the extra space for a higher bypass ratio and provides increased thrust as required while showing a much smaller specific fuel consumption. Main parameters of both engine designs are provided in Table 3 below.

\begin{tabular}{|l|c|c|c|c|}
\hline Parameter & Condition & Unit & Initial & Final \\
\hline \hline Static thrust & take-off & $\mathrm{kN}$ & 35.0 & 60.0 \\
Bypass ratio & cruise flight & - & 1.56 & 3.78 \\
Overall pressure ratio & take-off & - & 28.8 & 27.65 \\
Mass flow & take-off & $\frac{\mathrm{kg}}{\mathrm{s}}$ & 60.8 & 149.05 \\
Turbine entry temperature & take-off & $K$ & 1819.0 & 1835.95 \\
Specific fuel consumption & cruise flight & $\frac{\mathrm{g}}{\mathrm{kNs}}$ & 22.82 & 20.03 \\
Fan diameter & all & $\mathrm{m}$ & 0.65 & 1.12 \\
Length & all & $\mathrm{m}$ & 2.0 & 2.3 \\
Weight & all & $\mathrm{kg}$ & 700.0 & 1100.0 \\
\hline
\end{tabular}

Table 3. Engine parameters 
With this new aircraft size, the Excel spreadsheet was used to arrange the inner components in more detail so as to get the landing gear in the right place, to provide enough volume for fuel tanks and to find good locations for the other main components. The major task of this design step was to limit the longitudinal movement of the center of gravity in order to stay within the desired stability margins. Especially the highly swept fuel tanks with their long lever arm and a fuel mass that is nearly half of the take-off mass caused problems. By introducing a second pair of fuel tanks far in front of the center of gravity and by cutting the rear outer parts of the wing tanks, this stability problem could finally be solved. Positioning the payload bays close to the center of gravity further reduced the movement of the aircraft's center of gravity. A snapshot of the UCAV's main components and center of gravity locations after their re-

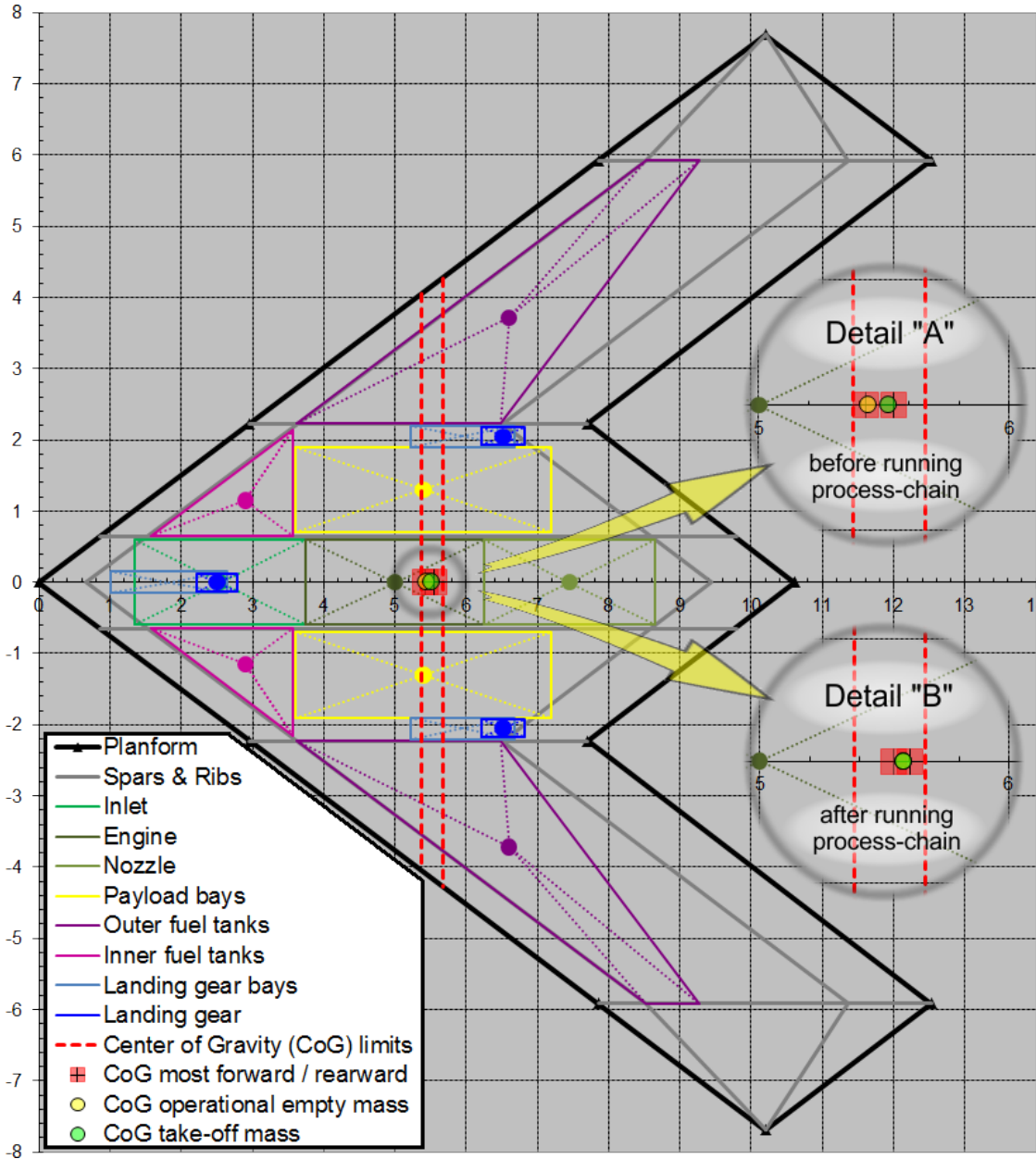

Figure 7. Main components of the UCAV configuration (Excel spreadsheet) ing the process chain is provided in Figure 7 (including Detail "A"). During the process, the initially estimated masses are continuously changing until the iteration loop converges. After achieving convergence, the final center of gravity locations (take-off mass for design mission without reserve fuel) are shown in Detail "B" of Figure 7.

One drawback of this Excel spreadsheet is that it does only contain a 2D model of the inner geometry, whereas the thickness of the UCAV varies continuously over the chord. As a consequence, it is not possible to determine from this model, whether a component really fits into the outer shape. As a solution to this problem, the spreadsheet was extended by a construction Table for Dassault's CATIA CAD software. ${ }^{23}$ Combined with an existing CAD model of the UCAV's outer shape, the CATIA software uses the construction Table to generate the inner components as specified in the Excel spreadsheet. When the spreadsheet changes during the progress of the process chain, the corresponding CATIA model is updated automatically as well. The CATIA 3D model of

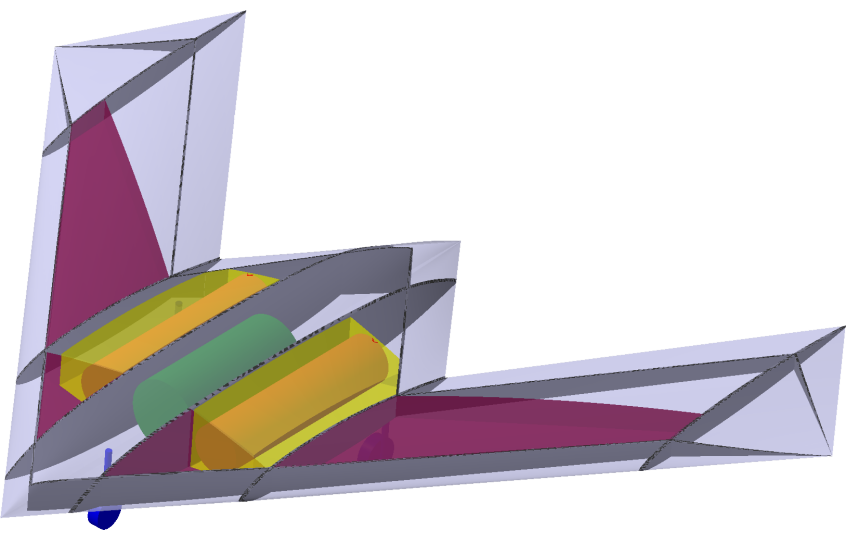
the UCAV configuration with its main compo-

Figure 8. UCAV 3D view with inner components (CATIA) nents is shown in Figure 8. 


\begin{tabular}{|l|r|r|r|r|r|r|r|}
\hline & & \multicolumn{3}{|c|}{ CG Coordinates } & \multicolumn{3}{c|}{ Mass Moments of Inertia $(\mathrm{CG})$} \\
Component & Mass $[\mathrm{kg}]$ & $X[\mathrm{~m}]$ & $Y[\mathrm{~m}]$ & $Z[\mathrm{~m}]$ & $I_{x x}\left[\mathrm{kgm}^{2}\right]$ & $I_{y y}\left[\mathrm{kgm}^{2}\right]$ & $I_{z z}\left[\mathrm{kgm}^{2}\right]$ \\
\hline \hline Structures & 2677 & 6.33 & 0.00 & 0.00 & 30486 & 3436 & 33922 \\
Landing Gear & 496 & 5.63 & 0.00 & 0.00 & 1514 & 1441 & 2955 \\
Propulsion & 1541 & 5.40 & 0.00 & 0.00 & 0 & 677 & 677 \\
Systems & 1790 & 4.65 & 0.00 & 0.00 & 0 & 7627 & 7627 \\
Other & 559 & 5.42 & 0.00 & 0.00 & 760 & 23 & 783 \\
Empty Mass & $\mathbf{7 0 6 2}$ & $\mathbf{5 . 5 8}$ & $\mathbf{0 . 0 0}$ & $\mathbf{0 . 0 0}$ & $\mathbf{3 2 ~ 7 6 0}$ & $\mathbf{1 3 2 0 4}$ & $\mathbf{4 5 ~ 9 6 4}$ \\
\hline \hline Payload & 2000 & 5.40 & 0.00 & 0.00 & 3380 & 62 & 3442 \\
Forward CG & $\mathbf{9 0 9 2}$ & $\mathbf{5 . 5 4}$ & $\mathbf{0 . 0 0}$ & $\mathbf{0 . 0 0}$ & $\mathbf{3 6 1 4 0}$ & $\mathbf{1 3 2 6 7}$ & $\mathbf{4 9} \mathbf{4 0 7}$ \\
\hline \hline Fuel & 5140 & 5.64 & 0.00 & 0.00 & 58498 & 19350 & 77849 \\
Rearward CG & $\mathbf{1 2 ~ 2 0 2}$ & $\mathbf{5 . 6 1}$ & $\mathbf{0 . 0 0}$ & $\mathbf{0 . 0 0}$ & $\mathbf{9 1 2 5 8}$ & $\mathbf{3 2 ~ 5 5 5}$ & $\mathbf{1 2 3} \mathbf{8 1 3}$ \\
\hline \hline Take-off mass & $\mathbf{1 4 2 0 2}$ & $\mathbf{5 . 5 8}$ & $\mathbf{0 . 0 0}$ & $\mathbf{0 . 0 0}$ & $\mathbf{9 4 6 3 8}$ & $\mathbf{3 2 ~ 6 1 7}$ & $\mathbf{1 2 7 2 5 5}$ \\
\hline
\end{tabular}

Table 4. Mass, CG location, and mass moments of inertia around CG

A mass breakdown of the UCAV is provided in Table 4. It contains the masses of the main components, their center of gravity locations in $X$-direction and the mass moments of inertia for the main axis'. The deviation moments are currently neglected, as well as the center of gravity locations in $Z$-direction (set to zero). The table is taken from the Excel spreadsheet after running the process chain and shows the case of take-off mass with full payload bays and fuel for the design mission (but excluding reserve fuel). For this mission, the available fuel tank volume is used only by $84.4 \%$. Taking an average fuelburn per time over the complete mission, the remaining $15.6 \%$ fuel volume $(\approx 950 \mathrm{~kg})$ would equal to an additional flight time of approx. 37 minutes. If using the extra fuel to extend especially the high altitude cruise flight (which is the most efficient flight phase), the additional flight time would increase to approx. 44 minutes. So the desired fuel reserve of approx. 45 minutes was finally met quite well. In the latter case, the take-off mass would increase to 15.15 metric tons, meeting the initially assumed 15.0 metric tons quite well, too.

The result from simulating the design mission with the final UCAV configuration is depicted in Figure 9. It shows altitude, angle of attack, Mach number and fuelflow over the mission duration and can be used to get a more detailed insight to the flight trajectory.

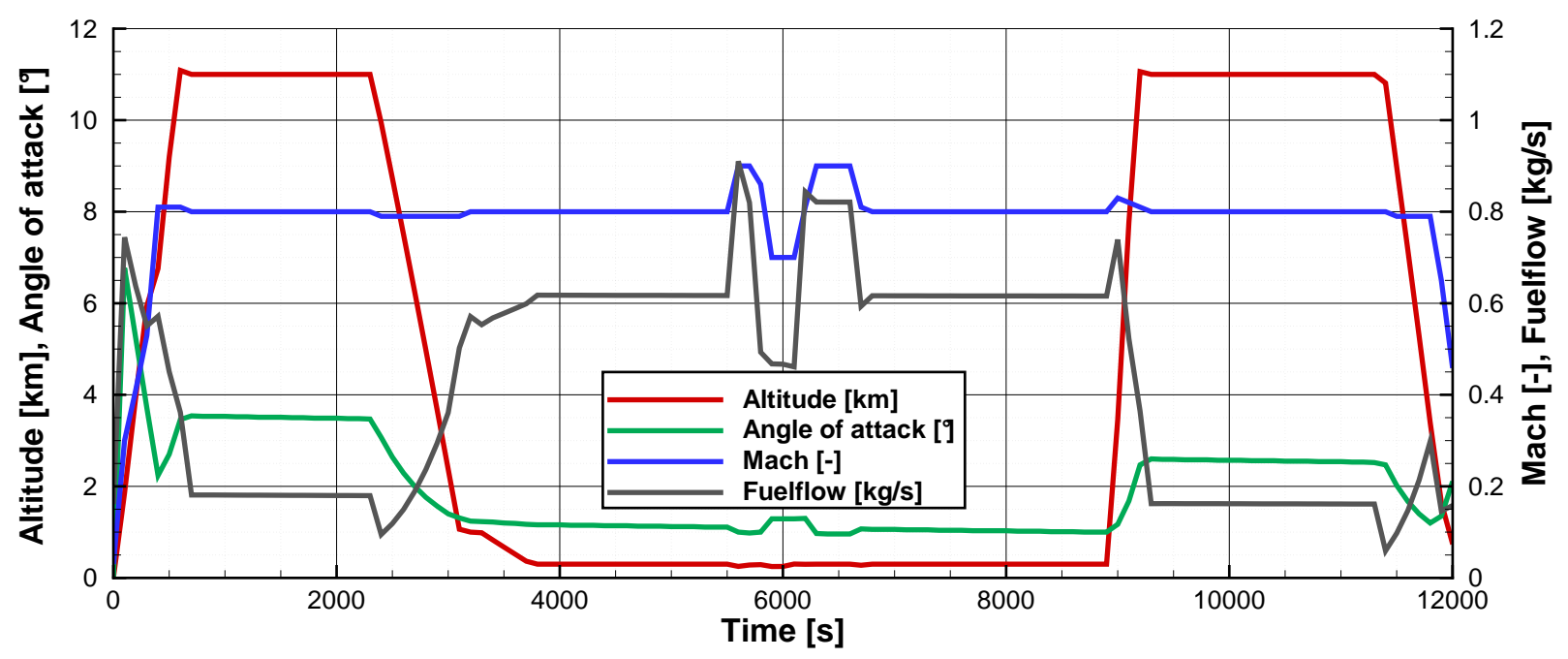

Figure 9. Trajectory of the simulated design mission 


\section{Aerodynamic analyses}

The conceptual design workflow described in the previous section needs an extensive amount of aerodynamic data for performance and load investigations. This database is currently created using simple and fast aerodynamic methods like VSAERO (used for the design study described in Chapter II) or LIFTING_LINE. VSAERO is a 3D singularity method based on the inviscid and incompressible potential flow theory, calculated on surface meshes. For investigating compressible flows, several compressibility corrections are included; viscous drag can optionally be considered through an iteratively coupled boundary layer module. LIFTING_LINE is running faster than VSAERO, but is based on the even more simplified skeleton theory (also called camberline theory). In skeleton theory, the 3D surface is reduced to a set of flat panels; hence it neglects all effects coming from thickness. Further simplifications include a limitation to small angles of attack and yaw. For compressible flows, LIFTING_LINE offers a compressibility correction as well. Over the years, VSAERO and LIFTING_LINE are well-proven for conventional transport aircraft configurations.

The question now is: How far can these simple methods be used for a highly swept flying wing aircraft? It is doubtless that the simple theory behind these tools is not able to model the complex vortex systems occuring for such aircraft, especially at higher angles of attack. On the other hand, this simple theory is known to behave conservatively in most cases. So the calculated loads are expected to be typically larger than what really will appear at the aircraft. Unfortunately this also means that control surface efficiencies might be much lower than expected. In this Chapter, results from LIFTING_LINE and VSAERO will be compared to measurements of the DLR-F19 windtunnel model (which was built from the SACCON geometry) ${ }^{24,25,26}$ and to RANS results created with the "DLR-TAU" code. ${ }^{27,28,29,30}$ The flow conditions for the comparison are defined by the windtunnel experiment: Mach number is 0.15 , Reynolds number is 1.6 million. TAU is a CFD tool developed by the DLR Institute of Aerodynamics and Flow Technology. It solves the compressible, three-dimensional, time-accurate RANS equations using a finite volume formulation. The code is based on a hybrid unstructured-grid approach, which makes use of the advantages that prismatic grids offer in the resolution of viscous shear layers near walls, and the flexibility in grid generation offered by unstructured grids. The TAU computations for this study were performed using the RSM ${ }^{\mathrm{k}}$ turbulence model. Details about this model and the complete computational setup can be found in Schütte et al. ${ }^{31}$ In order to have comparable results to LIFTING_LINE, VSAERO is used here without its boundary layer module. Instead, the HandbookAero tool is applied to calculate the turbulent viscous drag for VSAERO and LIFTING_LINE by using the method of the equivalent flat plate. The computational meshes of the three aerodynamic methods are depicted in Figure 11 on page 13, together with a photo of the DLR-F19 windtunnel model.

Control surface deflections in LIFTING_LINE and VSAERO are modeled just by rotating the normal vectors of the corresponding wing panels - but without changing the geometry itself. In LIFTING_LINE, the hinge line for control surface deflection is always projected into the global $Y$ - $Z$-Plane before use. This simplification of course leads to slightly different results which will be discussed below. In the 3D TAU mesh (as well as in the windtunnel model), the control surfaces are deflected geometrically, but without a gap. Figure 10 shows the control surface geometry used for LIFTING_LINE and VSAERO (left) and for TAU and the windtunnel model (right). On each side, there are two control surfaces: one inboard and one outboard. Regarding the side edges, the control surface definition used for LIFTING_LINE and VSAERO is not able to model the geometry from the windtunnel exactly. The simplification which is currently used even leads to slightly bigger control surfaces and will certainly produce a small over-prediction of control surface effects.

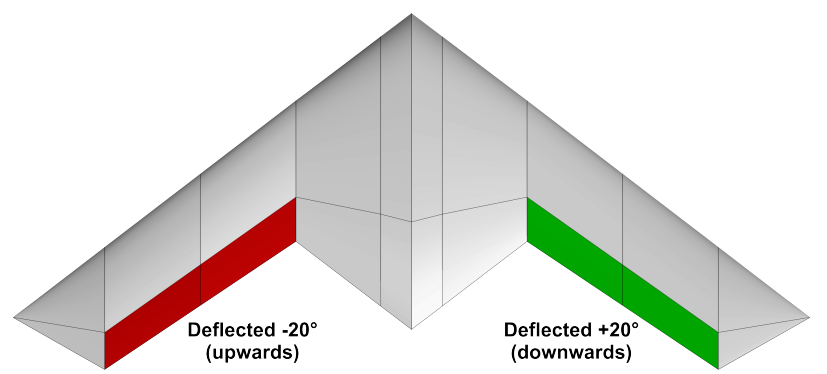

(a) LIFTING_LINE and VSAERO

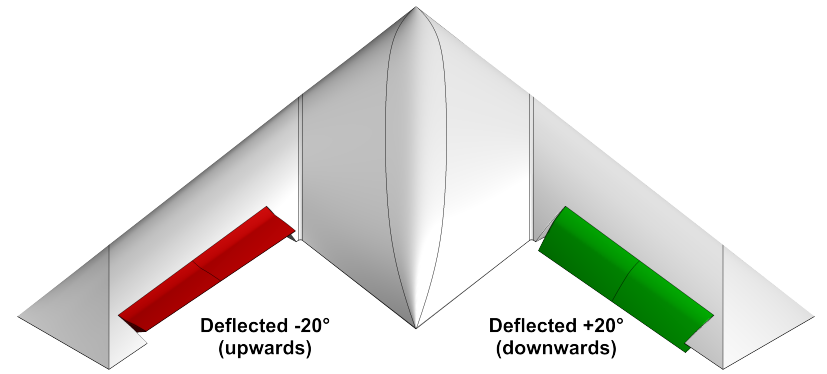

(b) TAU and windtunnel model

Figure 10. Differences in control surface geometry

\footnotetext{
${ }^{\mathrm{k}}$ Reynolds-Stress-Model
} 
Figure 12 on page 13 shows a comparison of the aerodynamic coefficients of the clean configuration for angles of attack from $0^{\circ}$ up to $15^{\circ}$. As can be seen, the LIFTING_LINE and VSAERO results agree quite well. Just for the pitching moment coefficient they show a slight deviation, especially for higher angles of attack. However, since the moment reference point is located very close to the neutral point, the deviation only means a small discrepancy in the position of the neutral point and must not be overestimated. Compared to TAU and the experimental data, the lift curve shows a marginally higher slope (which is typical for potential flow theory) and a minimal shift in the zero-lift angle. As it should be the case for a symmetrical geometry under symmetrical flow conditions, the side force coefficients are all zero - as well as the rolling and yawing moment coefficients. The drag curve of the TAU results differs significantly from the experimental results. The reason for this deviation is the influence coming from the sting of the windtunnel model. This was shown by a TAU simulation including the sting, performed by Schütte et al. ${ }^{31}$ The drag curves of LIFTING_LINE and VSAERO are quite similar to each other. For higher angles of attack they show drag coefficients which are much higher than the TAU results. In terms of pitching moment, there is again a strong deviation between TAU results and experimental data. This topic is also discussed in the above-mentioned article. In this case, a TAU computation with sting reduces the deviation and leads to similar gradients, but there is still an offset left between the two curves. As a reason for this offset, the article suspects that the flow topology coming from the sting is not predicted correctly by TAU. Comparing the pitching moment curves from LIFTING_LINE and VSAERO to the TAU results, it can be stated that they are in good agreement for low angles of attack. For angles of attack higher than $10^{\circ}$ the discrepancy increases due to vortex effects which are not modeled by the simple methods. Anyway, additional TAU computations for lower angles of attack are required in order to further assess the quality of drag and pitching moment coming from the simple methods.

In Figure 13 and Figure 14 on page 14, the differences due to a deflection of the inboard control surfaces are depicted. The left control surface is deflected upwards, whereas the right one is deflected downwards each one by an angle of $20^{\circ}$. The upper Figure shows the total coefficients, the lower one shows the control surface deltas (obtained by subtracting the clean configuration coefficients shown in Figure 12 on page 13 from the total coefficients with control surface deflection). Generally, it can be stated that the effect on lift, drag, and pitching moment coming from control surface deflection is very small. While LIFTING_LINE behaves strongly linear with nearly no dependency on the angle of attack, the other three curves show slight dependencies there. However, all four results are still in good agreement. The rolling moments from LIFTING_LINE and VSAERO are quite similar and - for low angles of attack - close to the measurements. Looking at higher angles of attack (around $10^{\circ}$ ), the rolling moments from TAU and windtunnel experiment begin to decrease whereas the moments from LIFTING_LINE and VSAERO stay nearly constant. This is exactly the expected behaviour for the simple methods: The control surface efficiency is slightly overpredicted and nearly independent from the angle of attack. For angles of attack close to $15^{\circ}$, the overprediction reaches a factor of nearly 2 . The influence on the yawing moment is generally quite small. Some small side force is predicted by the conceptual design methods, but not by RANS and measurements. For VSAERO, this seems to be an effect which is coming from mesh resolution and computational accuracy and will be further investigated in the future. For LIFTING_LINE, the simple geometry model consisting of flat plates with a slight dihedral due to wing twist creates an unrealistic side force which is proportional to the angle of attack.

The results from deflecting the outer control surfaces in the same way as the inner ones before (see Figure 15 and Figure 16 on page 15) are showing a similar trend as described above. The most interesting point in these two diagrams is that the rolling moments coming from the outer control surfaces are nearly identical or even smaller than the ones coming from the inner control surfaces. Another noticeable effect of the deflection of the outer control surfaces is that the rolling moments from LIFTING_LINE and VSAERO deviate from each other even for low angles of attack. This might be a result of the more complex flowfield generated by VSAERO close to the wingtip.

In Figure 17 and Figure 18 on page 16, inboard and outboard control surfaces of both sides are deflected. Again, the left side is deflected upwards by an angle of $20^{\circ}$, whereas the right one is deflected downwards by $20^{\circ}$. As expected, the coefficients show the same trends as for the isolated control surface deflections before. However, looking at higher angles of attack, the delta coefficients from TAU and experiment are not identical to the sum of isolated inboard and outboard delta coefficients. This means that the highly swept UCAV control surfaces are having a significant impact on each other due to $3 \mathrm{D}$ flow effects. Therefore, the combination of isolated control surface deflections by superposition of their delta coefficients - as commonly 
used for transport aircraft with low wing sweep - is not sufficient for high angles of attack. LIFTING_LINE and VSAERO are not predicting this cross-influence.

Finally, the effect of sideslip is depicted in Figure 19 on page 17. In order to display the effects clearly, an angle of attack of $10^{\circ}$ and a deflection of all control surfaces as described in Figure 17 is applied. The trends from VSAERO fit well to the results from TAU and from the windtunel measurements. The absolute values for the pitching moment are under-predicted, the rolling moment is significantly over-predicted. Taking into account that the absolute values are all quite low (except for the lift coefficient) the VSAERO results can be considered as sufficient here. Regarding LIFTING_LINE, it is obvious that there is nearly no influence from the sideslip angle. This effect is a result from the simplifications described above in combination with the SACCON geometry: In LIFTING_LINE, the SACCON geometry is nearly a totally flat plate. As the sideslip angle is considered to be small, the flow in $X$-direction is not reduced due to sideslip. Hence, the rolling moment coming from deflected control surfaces is slightly over-estimated and nearly independent from sideslip as well. On the other hand, the component from the incoming flow which is oriented in $Y$-direction does not create significant effects because the LIFTING_LINE geometry is nearly flat and the kinematic flow condition for each panel (including control surfaces) is evaluated in the $X$ - $Z$-plane only. As a consequence, LIFTING_LINE cannot predict the coefficients due to sideslip here.

\section{Conclusion}

DLR's conceptual design system was extended in order to permit design and analysis of highly swept flying wing UCAV configurations. A UCAV design task based on the generic NATO STO/AVT-161 SACCON geometry was specified and a conceptual design workflow for this task was created. Together with partners from several disciplines, the UCAV design was performed in a distributed process. A global scaling factor of 10 and an elaborated inner layout were the keys for fulfilling the design requirements. The question, whether simple and fast aerodynamic methods can provide suitable aerodynamic coefficients for such a configuration was investigated by comparison to RANS aerodynamics and windtunnel measurements. As a result it can be stated that the coefficients from simple aerodynamic methods can be sufficient as long as the angles of attack are kept low. The effects of deflected control surfaces are covered with a slight overestimation, but are still sufficient for low angles of attack. However, further investigations including TAU computations at lower angles of attack are still required in order to quantify the errors made by the simple methods. If an emphasis is placed on sideslip in combination with flat aircraft configurations, methods that are not neglecting thickness have to be used. At higher angles of attack, especially the pitching moment from simple methods might develop strong deviations to reality both in total values and trends. So, a mission analysis for fuel estimation can normally use coefficients from simple methods without problems. For the design of a flight control system or other flight dynamic investigations in the early stages of design, aerodynamic data coming purely from simple methods might not be sufficient. In such cases, a multi-fidelity approach could help to correct thousands of potential flow computations by a few well selected RANS computations or windtunnel measurements.

\section{Acknowledgement}

The design work presented here was performed in close cooperation with DLR-colleagues from all involved disciplines, namely aeroelastics, flight mechanics and systems, infrared-signatures, propulsion, radarsignatures, structures, system dynamics and control. The authors would like to thank all colleagues who contributed to this design work. An additional acknowledgement has to be given to the colleagues from DLR's simulation and software technology branch, as well as to the community of DLR's conceptual design system. 


\section{References}

${ }^{1}$ Vicroy, D. D., Huber, K. C., Loeser, T., and Rohlf, D., "Low-speed Dynamic Wind Tunnel Test Analysis of a Generic $53^{\circ}$ Swept UCAV Configuration with Controls," 32nd AIAA Applied Aerodynamics Conference, No. AIAA-2014-2003, Atlanta, GA, June 2014.

${ }^{2}$ Liersch, C. M. and Hepperle, M., "A Unified Approach for Multidisciplinary Preliminary Aircraft Design," CEAS 2009 European Air and Space Conference, October 2009.

${ }^{3}$ Liersch, C. M. and Hepperle, M., "A distributed toolbox for multidisciplinary preliminary aircraft design," CEAS Aeronautical Journal, Vol. 2, No. Number 1-4, December 2011, pp. 57-68.

${ }^{4}$ Nagel, B., Zill, T., Moerland, E., and Böhnke, D., "Virtual Aircraft Multidisciplinary Analysis and Design Processes Lessons Learned from the Collaborative Design Project VAMP," CEAS 2013 European Air and Space Conference, September 2013.

${ }^{5}$ Nagel, B., Böhnke, D., Gollnick, V., Schmollgruber, P., Rizzi, A., Rocca, G. L., and Alonso, J. J., "Communication in Aircraft Design: Can we establish a Common Language?" 28th International Congress of the Aeronautical Sciences (ICAS), 2012.

${ }^{6}$ Bachmann, A., Kunde, M., Litz, M., and Schreiber, A., "A dynamic data integration approach to build scientific workflow systems," International workshop on workflow management (IWWM 2009), The institute of electrical and electronics engineers, Inc., May 2009, pp. 27-33.

7 "CPACS Homepage," URL: http://software.dlr.de/p/cpacs/home/ [cited 19 May 2014].

8 "TiXI Homepage," URL: http://software.dlr.de/p/tixi/home/ [cited 19 May 2014].

9 "TiGL Homepage," URL: http://software.dlr.de/p/tigl/home/ [cited 19 May 2014]

10 "ModelCenter Homepage," URL: http://www.phoenix-int.com/software/phx-modelcenter.php [cited 19 May 2014 ].

${ }^{11}$ Seider, D., Fischer, P., Litz, M., Schreiber, A., and Gerndt, A., "Open Source Software Framework for Applications in Aeronautics and Space," IEEE Aerospace Conference, March 2012.

12 "RCE Homepage," URL: http://software.dlr.de/p/rcenvironment/home/ [cited 19 May 2014].

${ }^{13}$ Cummings, R. and Schütte, A., "An Integrated Computational/Experimental Approach to UCAV Stability \& Control Estimations: Overview of NATO RTO AVT-161," 28th AIAA Applied Aerodynamics Conference, No. AIAA-2010-4392, 2010.

${ }^{14}$ Becker, R.-G., Wolters, F., Nauroz, M., and Otten, T., "Development of a Gas Turbine Performance Code and its Application to Preliminary Engine Design," DLRK 2011, September 2011.

15 "VSAERO Homepage," URL: http://www.ami.aero/software-computing/amis-computational-fluid-dynamics-tools/ vsaero/[cited 21 May 2014].

${ }^{16}$ Horstmann, K. H., "Ein Mehrfach-Traglinienverfahren und seine Verwendung für Entwurf und Nachrechnung nichtplanarer Flügelanordnungen," Tech. rep., Deutsche Forschungs- und Versuchsanstalt für Luft- und Raumfahrt, 1987.

${ }^{17}$ Liersch, C. M. and Wunderlich, T. F., "A Fast Aerodynamic Tool for Preliminary Aircraft Design," 12th AIAA / ISSMO Multidisciplinary Analysis and Optimization Conference, No. AIAA-2008-5901, September 2008.

${ }^{18}$ Looye, G., "TECS/THCS-based generic autopilot control laws for aircraft mission simulation," Second CEAS Specialist Conference on Guidance, Navigation and Control, June 2013.

${ }^{19}$ Krüger, W., Cumnuantip, S., and Liersch, C., "Multidisciplinary Conceptual Design of a UCAV Configuration," RTO/AVT Panel Workshop "Virtual Prototyping of Affordable Military Vehicles Using Advanced MDO", 2011.

${ }^{20} \mathrm{Klimmek}, \mathrm{T}$., "Parameterization of Topology and Geometry for the Multidisciplinary Optimization of Wing Structures," CEAS 2009 European Air and Space Conference, October 2009.

${ }^{21}$ Duus, G. and Duda, H., "HAREM - HAndling Qualities Research and Evaluation using Matlab," IEEE International Symposium on Computer Aided Control System Design, Kohala Coast, HI (us), 22-27 August 1999, 1999, pp. 428-432.

${ }^{22}$ Ehlers, J., "Flying Qualities Analysis of CPACS Based Aircraft Models - HAREM V2.0 -," Tech. rep., German Aerospace Center (DLR), Institute for Flight Systems, June 2013.

23 "CATIA Homepage," URL: http://www.3ds.com/de/produkte-und-services/catia/[cited 22 May 2014].

${ }^{24}$ Löser, T., Vicroy, D., and Schütte, A., "SACCON Static Wind Tunnel Tests at DNW-NWB and 14'x22' NASA LaRC," 28th AIAA Applied Aerodynamics Conference, No. AIAA-2010-4393, 2010.

${ }^{25}$ Vicroy, D. D., Loeser, T. D., and Schütte, A., "Static and Forced-Oscillation Tests of a Generic Unmanned Combat Air Vehicle," Journal of Aircraft, Vol. Volume 49, No. 6, November 2012, pp. 1558-1583.

${ }^{26}$ Huber, K. C., Vicroy, D., Schütte, A., and Hübner, A. R., "UCAV model design and static experimental investigations to estimate control device effectiveness and Stability and Control capabilities," 32nd AIAA Applied Aerodynamics Conference, No. AIAA-2014-2002, Atlanta, GA, June 2014.

${ }^{27}$ Galle, M., Gerhold, T., and Evans, J., "Technical Documentation of the DLR TAU-Code," Tech. Rep. DLR-IB 23397/A43, DLR, 1997.

${ }^{28}$ Gerhold, T., Friedrich, O., Evans, J., and Galle, M., "Calculation of Complex Three-Dimensional Configurations Employing the DLR-tau-Code," 35th Aerospace Sciences Meeting \& Exhibit, January 6-10, 1997, Reno, NV, No. AIAA-1997-0167, January 1997.

${ }^{29}$ Gerhold, T., "Overview of the Hybrid RANS Code TAU," Closing Presentation DLR Project MEGAFLOW, Braunschweig (de), 10.-11.12.2002, edited by N. Kroll and J. Faßbender, Vol. 89 of Notes on Numerical Fluid Mechanics and Multidisciplinary Design (NNFM), Springer Verlag, 2005.

${ }^{30}$ Schwamborn, D., Gerhold, T., and Heinrich, R., "The DLR TAU-Code: Recent Applications in Research And Industry," ECCOMAS CFD 2006 Conference, 2006.

${ }^{31}$ Schütte, A., Huber, K. C., and Boelens, O. J., "Static and dynamic numerical simulations of a generic UCAV configuration with and without control devices," 32nd AIAA Applied Aerodynamics Conference, No. AIAA-2014-2132, Atlanta, GA, June 2014 . 


\section{Appendix}

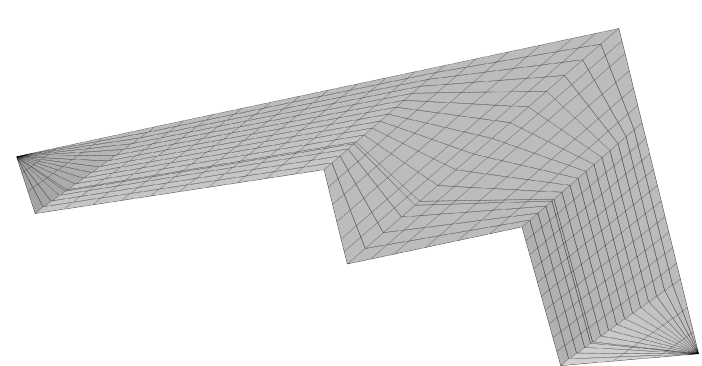

(a) LIFTING_LINE mesh

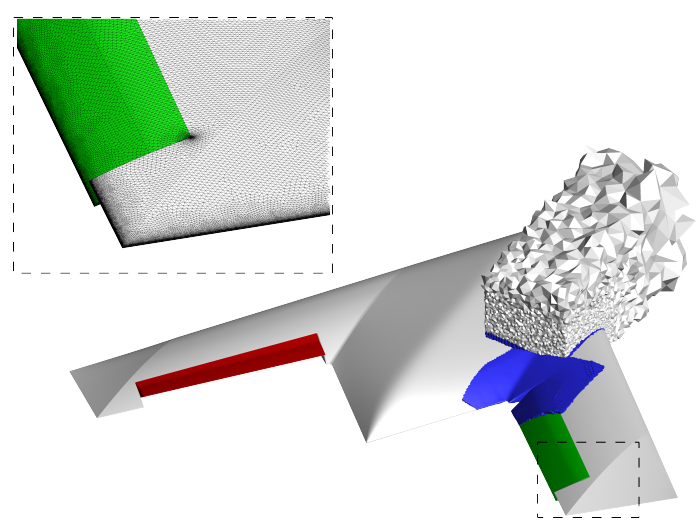

(c) TAU mesh

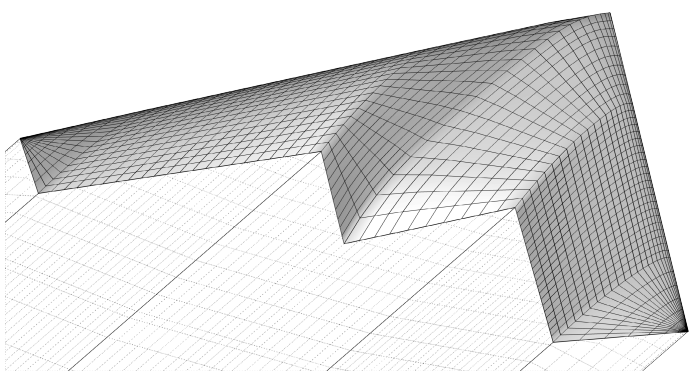

(b) VSAERO mesh

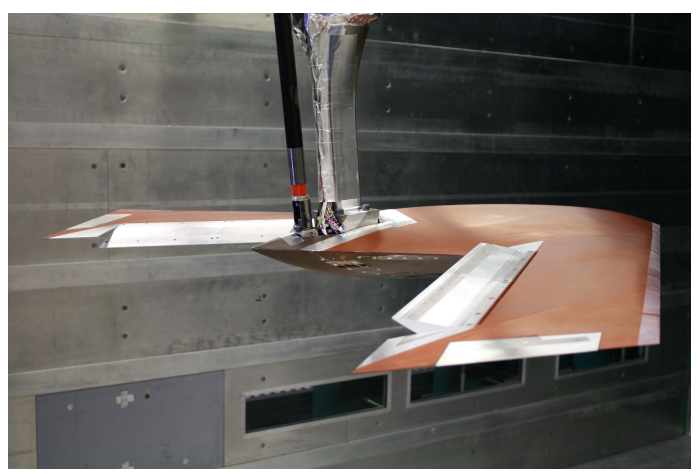

(d) DLR-F19 Windtunnel model

Figure 11. Aircraft models for computation and windtunnel measurements
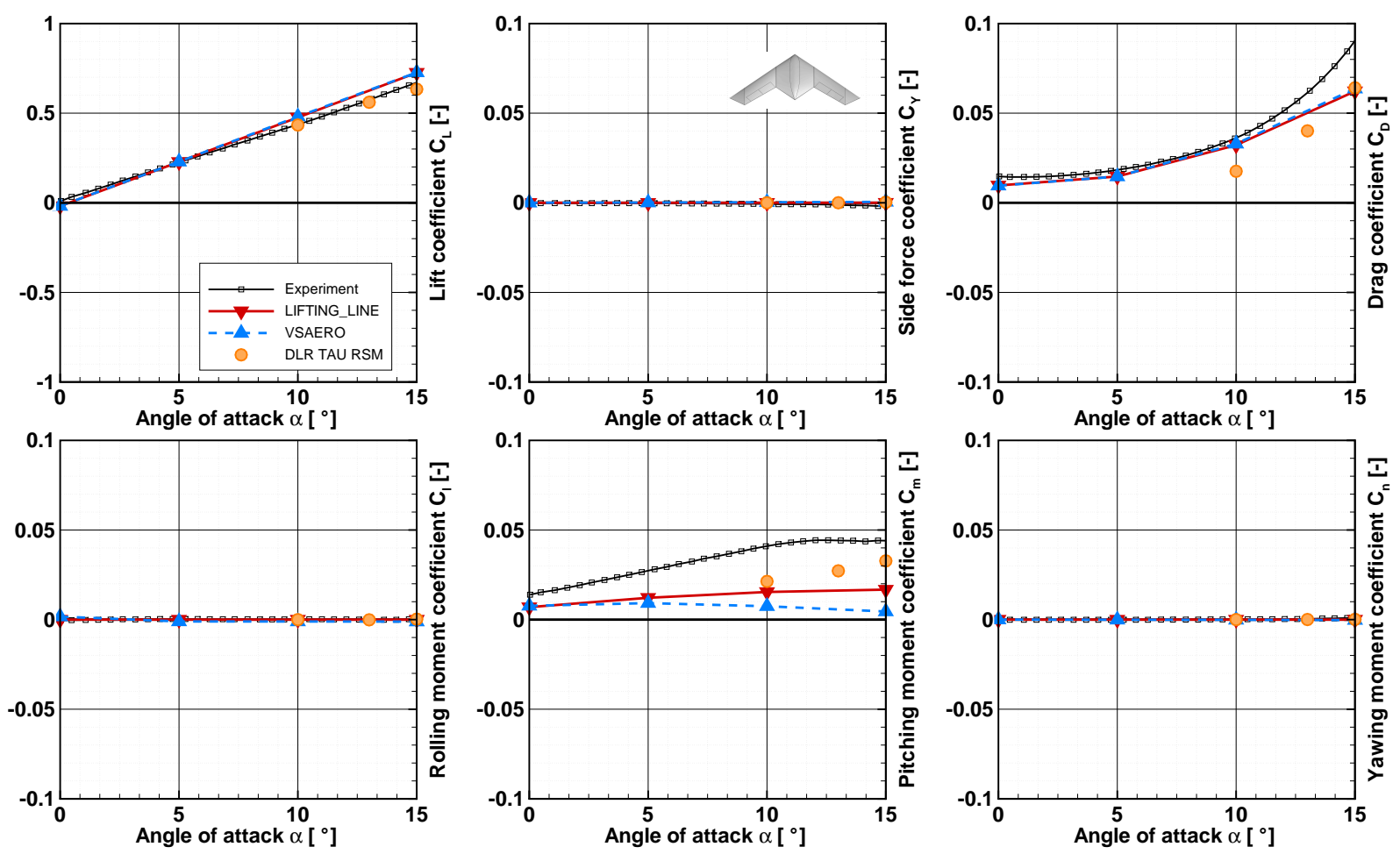

Figure 12. Total coefficients of clean configuration $\left(M=0.15, R E=1.6 \cdot 10^{6}\right)$ 

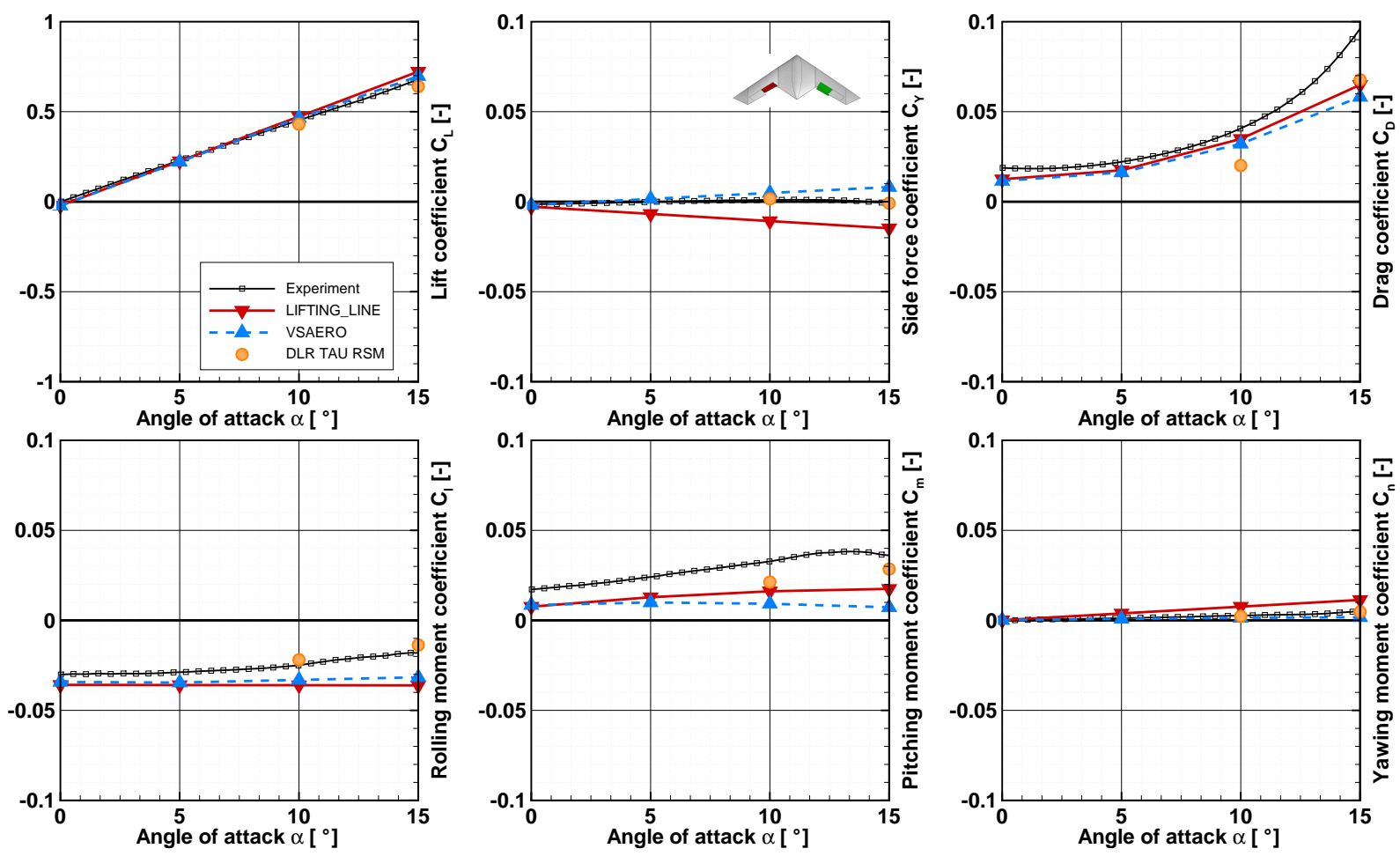

Figure 13. Total coefficients of configuration with deflected inboard control surfaces
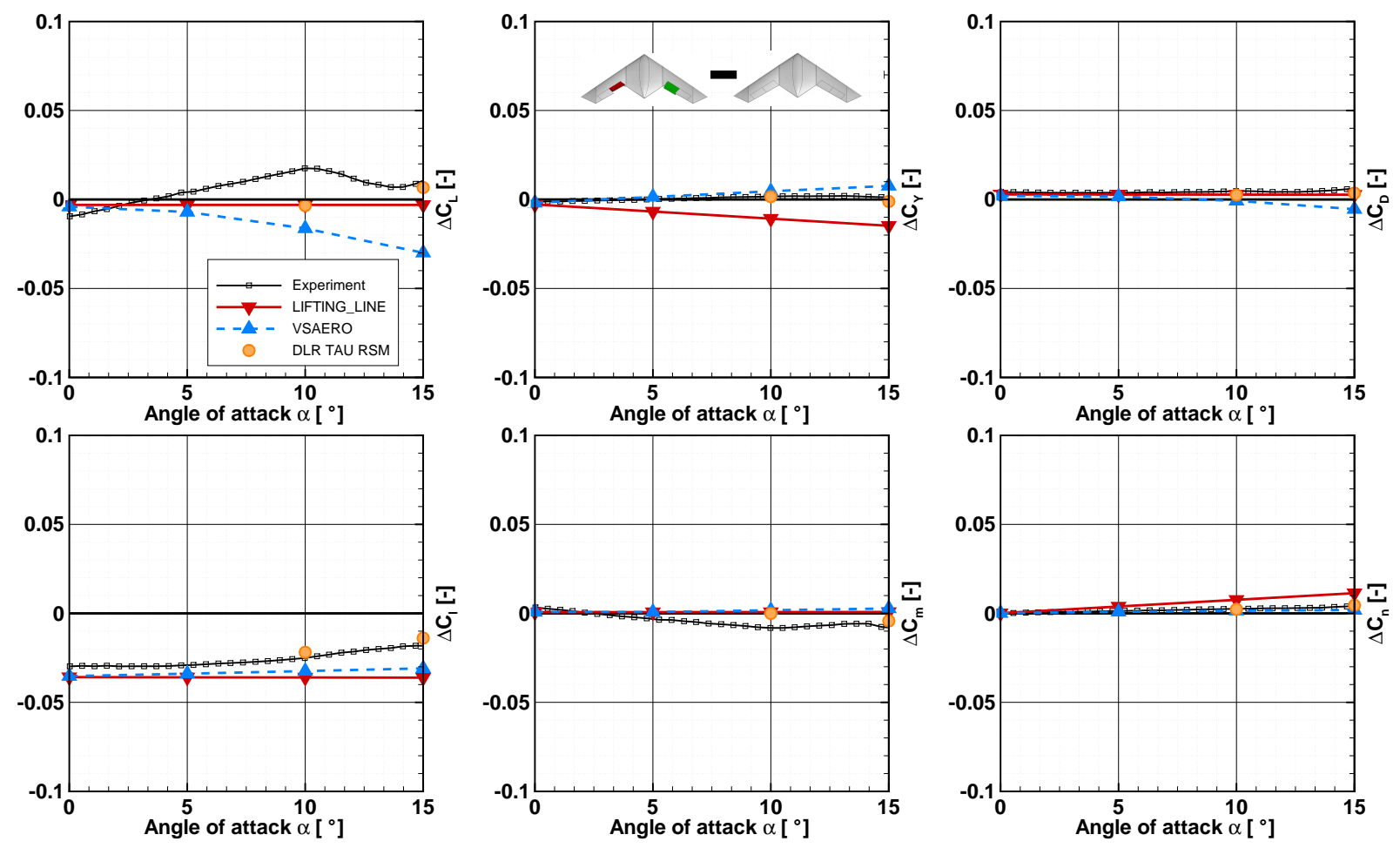

Figure 14. Delta coefficients due to deflected inboard control surfaces 

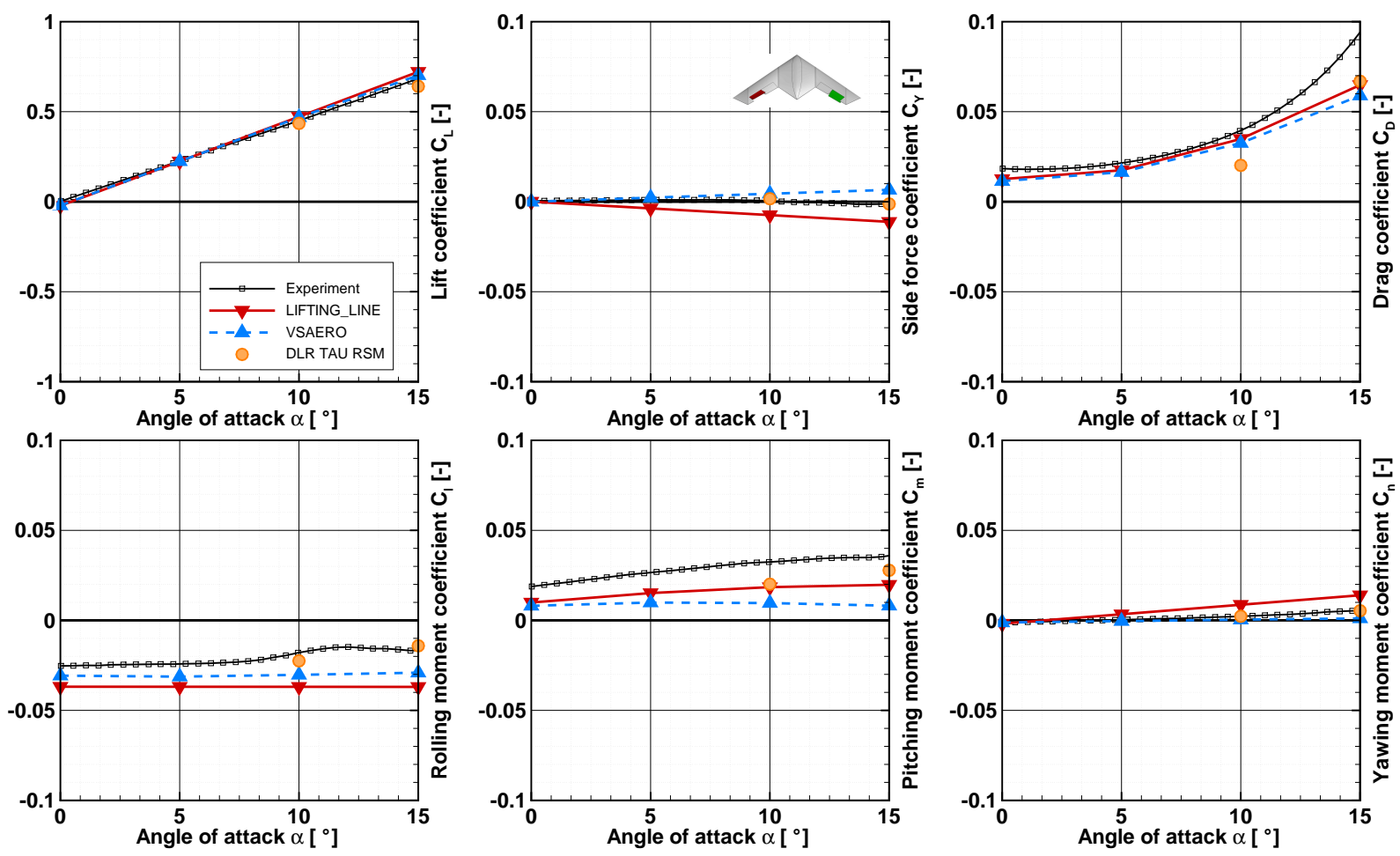

Figure 15. Total coefficients of configuration with deflected outboard control surfaces
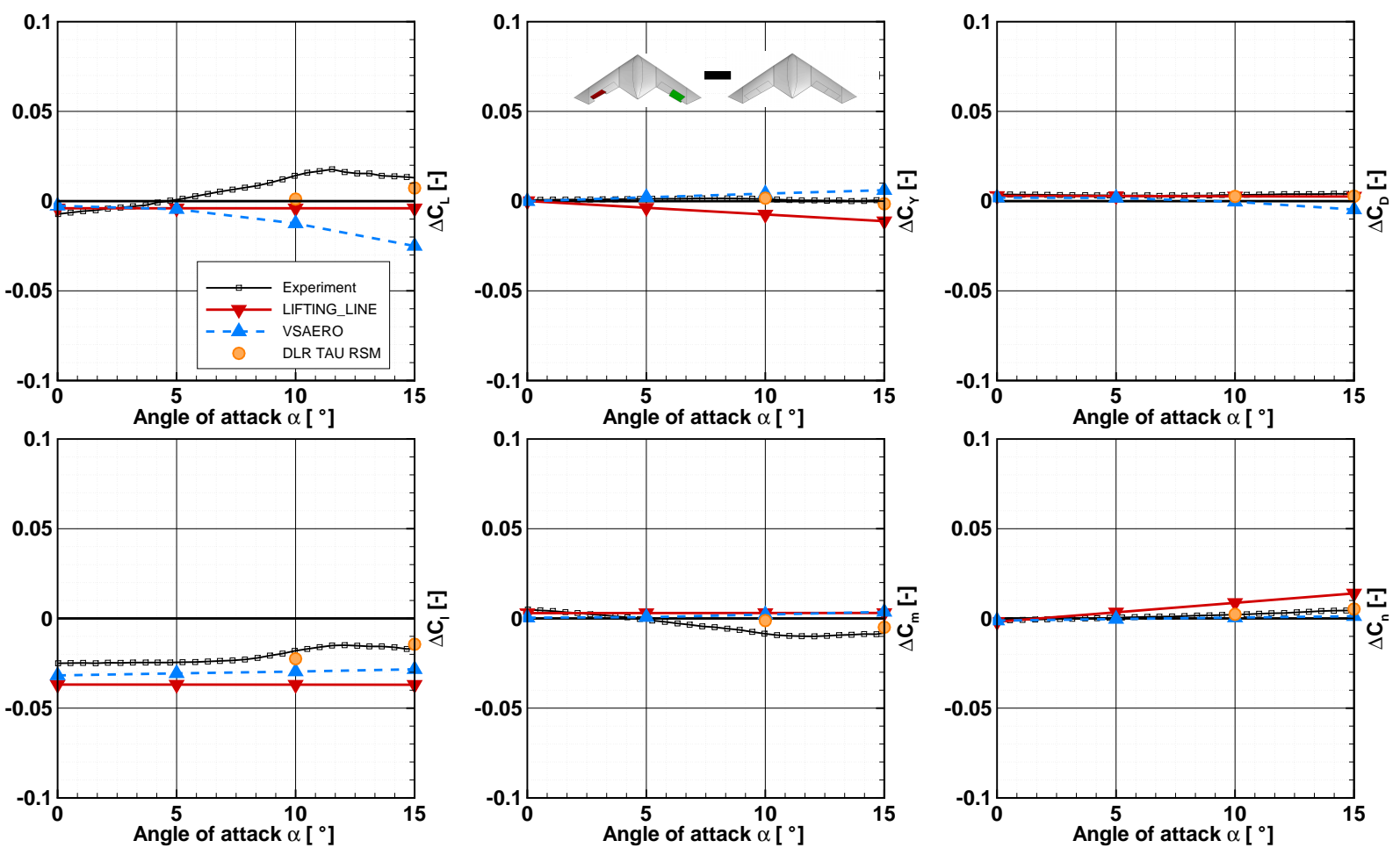

Figure 16. Delta coefficients due to deflected outboard control surfaces 

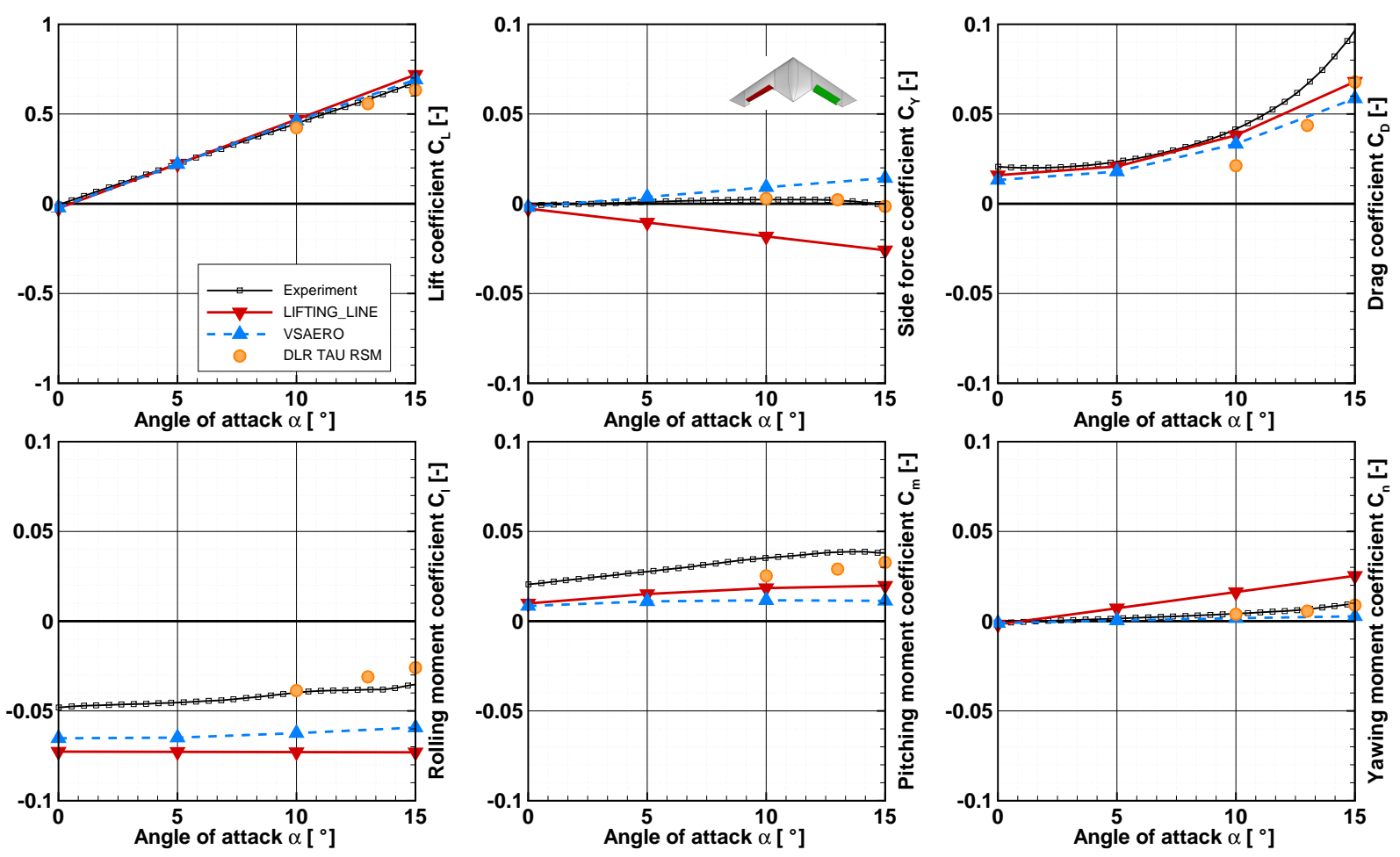

Figure 17. Total coefficients of configuration with deflected inboard and outboard control surfaces
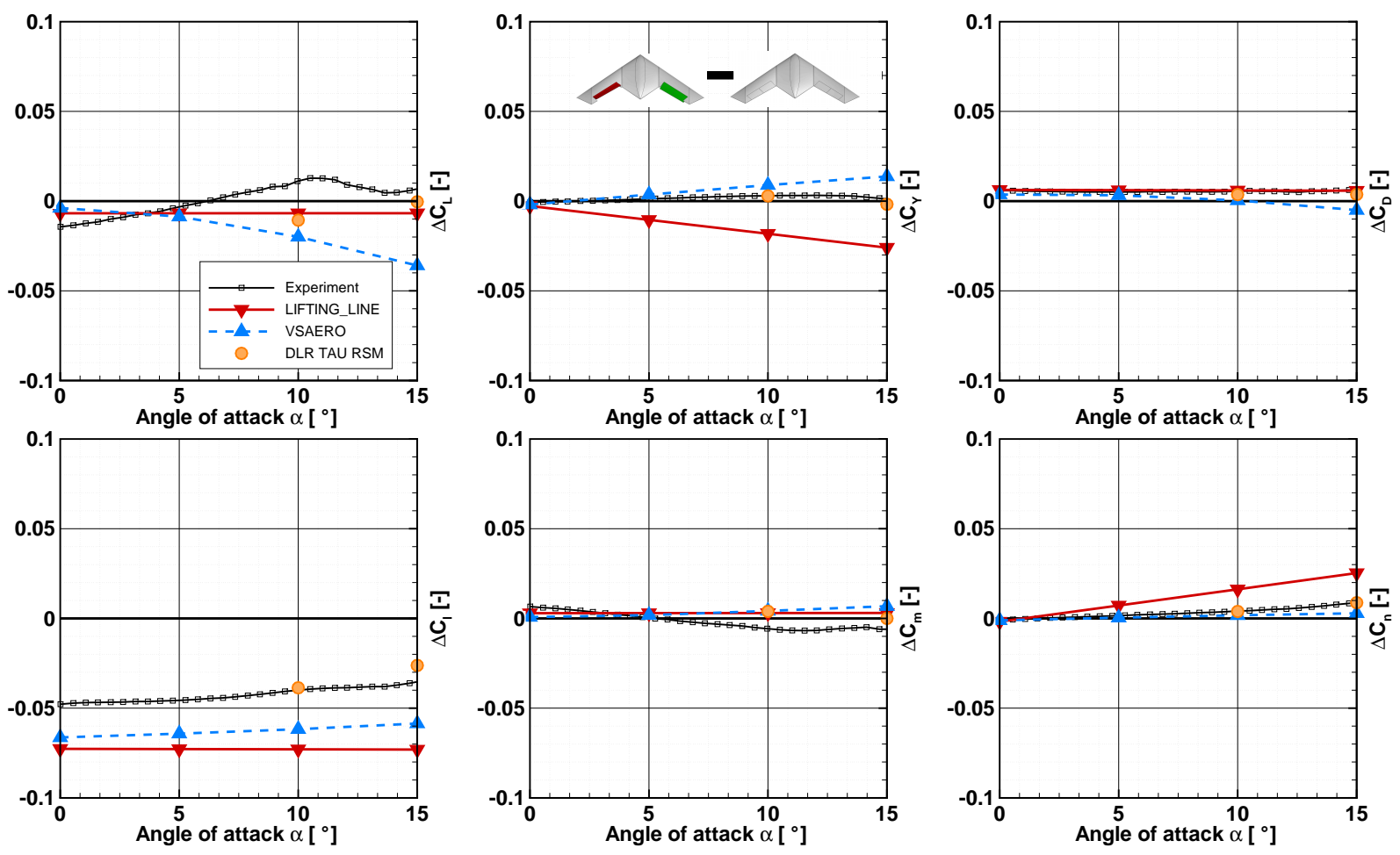

Figure 18. Delta coefficients due to deflected inboard and outboard control surfaces 

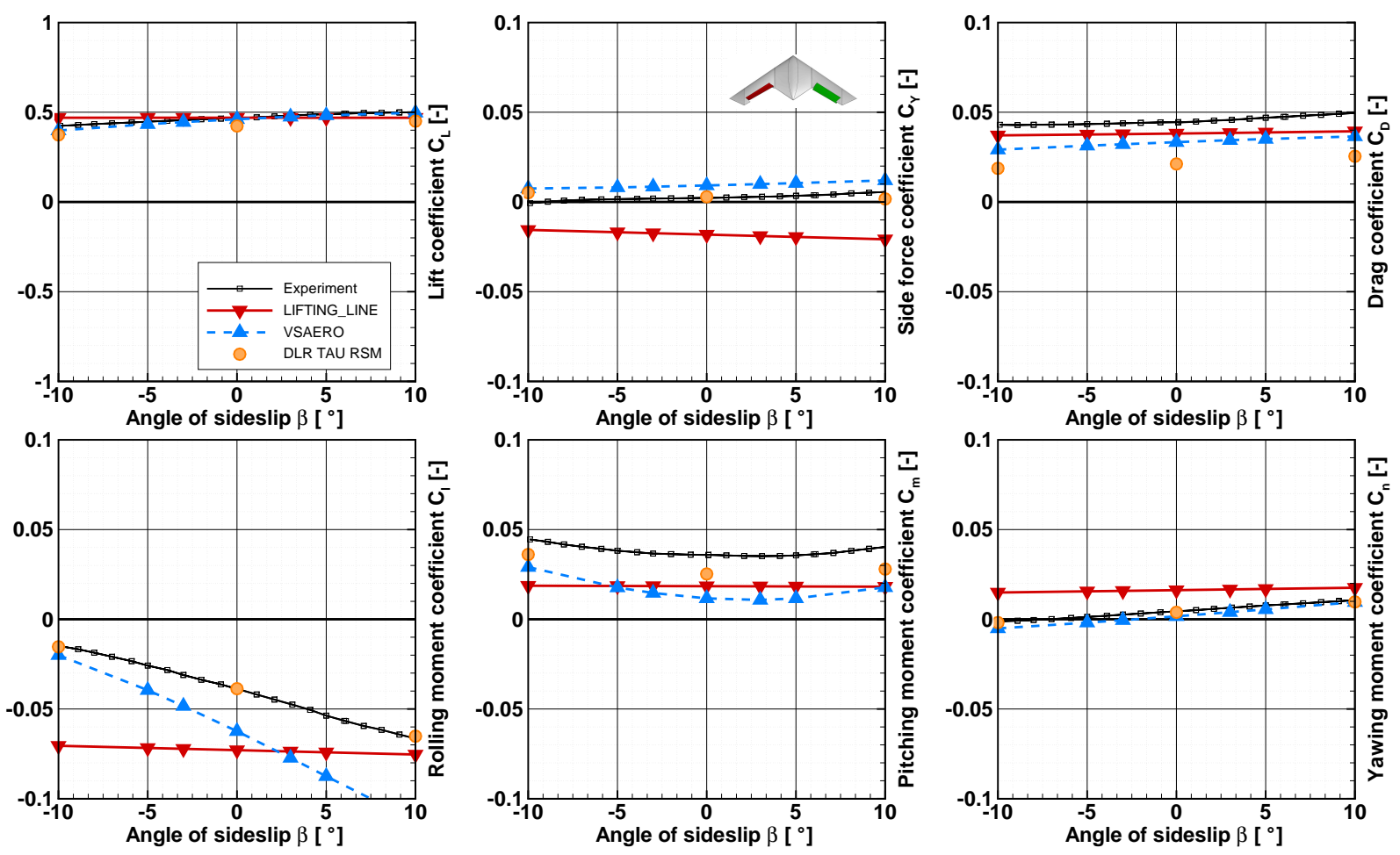

Figure 19. Total coefficients of configuration with deflected inboard and outboard control surfaces, $\alpha=10^{\circ}$ 